\title{
SISTEM INFORMASI PENGADUAN LAYANAN PADA BPKAD PROVINSI NUSA TENGGARA BARAT BERBASIS WEB
}

\author{
(Information System of Complaint Services BPKAD Province of West Nusa Tenggara \\ Based on Web)
}

\author{
Mitha Amara $^{[1]}$, Andy Hidayat Jatmika ${ }^{[1]}$, Lalu Miftahul Ulum ${ }^{[2]}$ \\ ${ }^{[1]}$ Dept of Informatics Engineering, University of Mataram \\ Jl. Majapahit 62, Mataram, Lombok NTB, INDONESIA \\ ${ }^{[2]}$ UPTB Pelayanan Perbendaharaan Wilayah Pulau Lombok \\ BPKAD Provinsi NTB, Mataram, Lombok NTB, INDONESIA \\ Email:mithacherryz@gmail.com, andy@unram.ac.id, el.ulum82@gmail.com
}

\begin{abstract}
Abstrak
Seiring berkembangnya zaman, perkembangan teknologi informasi semakin pesat dan banyak digunakan dalam berbagai bidang kehidupan seperti pendidikan, kesehatan, perkantoran dan lain-lain. Salah satu perkembangan teknologi yang berkembang di masyarakat saat ini adalah teknologi internet. Dalam perkembangannya, teknologi internet tak lepas dari perkembangan sistem informasi yang pada saat ini banyak digunakan untuk mengelola dan menyajikan data secara efektif dan efisien. Dalam pengelolaan data keluhan masyarakat di Badan Pengelolaan Keuangan dan Aset Daerah (BPKAD) Provinsi Nusa Tenggara Barat, proses penanganan keluhan dan monitoring data masih dilakukan secara manual sehingga kurang efektif. Dengan adanya permasalahan tersebut, maka penulis membuat "Sistem Informasi Pengaduan Layanan BPKAD Provinsi Nusa Tenggara Barat Berbasis Web" dengan menggunakan bahasa pemrograman PHP dan database MySQL yang diharapkan dapat membantu pegawai BPKAD Provinsi NTB dalam pengelolaan data keluhan masyarakat secara lebih efektif dan efisien. Berdasarkan sistem yang dibuat, didapatkan hasil pengujian sistem pada responden yang merupakan pegawai BPKAD Provinsi NTB yaitu sebesar 96\% responden setuju dengan sistem yang dibuat dapat memudahkan pengelolaan data keluhan bagi pegawai.
\end{abstract}

Keywords: Pengaduan, Sistem Informasi, Teknologi Informasi, PHP, MySQL.

\section{Pendahuluan}

\subsection{Latar Belakang}

Perkembangan sistem informasi dan teknologi komputer saat ini sedang mengalami peningkatan yang cukup signifikan, hal ini sejalan dengan kebutuhan masyarakat terhadap informasi. Dinamika masyarakat yang cenderung cepat mengikuti arus perkembangan teknologi menuntut adanya ketersediaan informasi yang cepat, tepat dan akurat. Teknologi informasi adalah salah satu contoh produk teknologi yang berkembang pesat yang dapat membantu manusia dalam mengolah data serta menyajikan sebuah informasi yang berkualitas.

Badan Pengelolaan Keuangan dan Aset Daerah Provinsi (BPKAD) Nusa Tenggara Barat (NTB) adalah suatu badan/institusi yang merupakan gabungan dari sub Bagian Perlengkapan pada Biro Umum Sekretariat Daerah (Setda) Provinsi Nusa Tenggara Barat dan eks Biro Keuangan Setda Provinsi Nusa Tenggara Barat. BPKAD Provinsi NTB bertugas untuk memudahkan dalam menyelesaikan permasalahan aset maupun keuangan yang kompleks. Terlebih beberapa urusan di Kabupaten/Kota akan diserahkan urusannya kepada Pemerintah Provinsi dalam pengelolaan keuangan dan aset.

BPKAD Nusa Tenggara Barat didukung oleh sumber daya manusia sebanyak 146 orang. Dalam proses pengaduan pelayanan BPKAD dilakukan secara manual dan terdapat beberapa kendala yaitu sulitnya melakukan perekapan data dalam bentuk hardcopy, pengaduan tidak tercatat dengan sempurna, sulit mencari data, sering terjadi pencatatan ganda, dan kehilangan data. Oleh karena itu, dibutuhkan sebuah sistem database yang dapat menghubungkan pihak terkait (BPKAD dan masyarakat). Sistem menyediakan hak akses bagi pihak BPKAD dan juga masyarakat sehingga pengelolaan pengaduan lebih optimal.

Berdasarkan uraian dan Analisa yang telah dilakukan, dalam rangka pengabdian kepada masyarakat, penulis akan membuat sebuah sistem informasi yang dapat menampung dan mengelola keluhan masyarakat pada BPKAD provinsi NTB yang berbasis web dengan menggunakan Bahasa PHP untuk dapat menyajikan data secara efisien yang diharapkan dapat membantu pihak Kantor BPKAD Provinsi Nusa Tenggara Barat dalam melakukan pengelolaan terhadap keluhan masyarakat. 
Tujuan dari pembuatan sistem informasi pengaduan layanan di Kantor BPKAD Provinsi Nusa Tenggara Barat antara lain sebagai berikut :

a. Untuk merancang dan membangun sistem informasi pengaduan layanan berbasis web untuk kantor BPKAD Provinsi Nusa Tenggara Barat.

b. Untuk membantu pegawai dalam melakukan pengelolaan keluhan masyarakat secara lebih efektif dan efisien.

Manfaat dari pembuatan sistem informasi pengaduan layanan di Kantor BPKAD Provinsi Nusa Tenggara Barat ini adalah sebagai berikut :

a. Memudahkan pegawai BPKAD Provinsi Nusa Tenggara Barat untuk dapat mengamati pengaduan masyarakat dengan lebih terbuka.

b. Pengelolaan data-data keluhan masyarakat yang lebih transparan dan juga efektif bagi masyarakat dan pegawai.

\section{Tinjauan PUStaka}

\subsection{Sistem}

Sistem adalah suatu jaringan kerja dari prosedur-prosedur yang saling berhubungan, berkumpul bersamasama untuk melakukan kegiatan atau untuk melakukan sasaran yang tertentu. Pendekatan sistem yang merupakan jaringan kerja dari prosedur lebih menekankan urutan-urutan operasi di dalam sistem. Menurut Richard F. Neuschel suatu prosedur adalah suatu urutan operasi klerikal (tulis-menulis), yang melibatkan beberapa orang di dalam satu atau lebih departemen, yang diterapkan untuk menjamin penanganan yang seragam dari transaksi-transaksi bisnis yang terjadi [1].

\subsection{Informasi}

Informasi adalah data yang diolah menjadi bentuk yang lebih berguna dan lebih berarti bagi penerimanya. Sumber informasi adalah data. Data kenyataan yang menggambarkan suatu kejadian-kejadian dan kesatuan nyata. Kejadian-kejadian (event) adalah kejadian yang terjadi pada saat tertentu. Menurut Gordon B. Davis: Informasi adalah data yang telah diolah menjadi suatu bentuk yang penting bagi si penerima dan mempunyai nilai nyata atau yang dapat dirasakan dalam keputusan-keputusan yang sekarang atau keputusan-keputusan yang akan datang [1].

\subsection{Sistem Informasi}

Dalam arti yang luas sistem informasi dapat dipahami sebagai sekumpulan sub sistem yang saling berhubungan, berkumpul bersama-sama dan membentuk satu kesatuan, saling berintegrasi dan bekerja sama antara bagian satu dengan yang lainnya dengan cara-cara tertentu untuk melakukan fungsi pengolahan data, menerima masukan (input) berupa data-data, kemudian mengolahnya (processing), dan menghasilkan keluaran (output) berupa informasi sebagai dasar pengambilan keputusan yang berguna dan mempunyai nilai nyata yang dapat dirasakan akibatnya baik pada saat itu juga maupun dimasa mendatang, mendukung kegiatan operasional, manajerial, dan strategis organisasi, dengan memanfaatkan berbagai sumber daya yang ada dan tersedia bagi fungsi tersebut guna mencapai tujuan. Berdasarkan definisi tersebut, dapat disimpulkan bahwa sistem informasi merupakan data yang dikumpulkan, dikelompokkan dan diolah sedemikian rupa sehingga menjadi sebuah satu kesatuan informasi yang saling dan saling mendukung sehingga menjadi informasi yang berharga bagi yang menerimanya [2].

\subsection{Database/Basis Data}

Basis data (Database) merupakan kumpulan dari data yang saling berhubungan satu dengan lainnya, tersimpan di perangkat keras komputer dan digunakan perangkat lunak untuk memanipulasinya. Sebuah basis data adalah tempat penyimpanan file data. Sebagai file data, suatu basis data tidak dapat menyajikan informasi secara langsung kepada pengguna. Pengguna harus menjalankan aplikasi untuk mengakses data dari basis data dan menyajikannya dalam bentuk yang bisa dimengerti [3].

\subsection{Aplikasi Berbasis Web}

Website atau situs dapat diartikan sebagai kumpulan halaman-halaman yang digunakan untuk menampilkan informasi teks, gambar diam atau gerak, animasi, suara, dan atau gabungan dari semuanya baik yang bersifat statis maupun dinamis yang membentuk satu rangkaian bangunan yang saling terkait, yang masing-masing dihubungkan dengan jaringan-jaringan halaman. Hubungan antara satu halaman web dengan halaman web yang lainnya disebut hyperlink, sedangkan teks yang dijadikan media penghubung disebut hypertext. Ada beberapa hal yang dipersiapkan untuk membangun website gratis, maka harus tersedia unsur-unsur pendukungnya sebagai berikut: 
a. Nama Domain (Domain name/URL - Uniform Resource Locator)

b. Rumah Website

c. Content Management System (CMS)

Perkembangan dunia website pada saat ini lebih menekankan pada pengelolaan content adalah sebuah website. Pengguna yang tidak bisa bahasa pemrograman website pada saat ini bisa membuat website dengan memanfaatkan CMS tersebut [4].

\subsection{Pemodelan Aplikasi dan Sistem Perangkat Lunak}

Unified Modeling Language (UML) merupakan bahasa visual untuk pemodelan dan komunikasi mengenai sebuah sistem dengan menggunakan diagram dan teks-teks pendukung [5]. Unified Modeling Language (UML) adalah sebuah bahasa yang berdasarkan grafik/gambar untuk memvisualisasi menspesifikasikan dari sebuah sistem pengembangan software berbasis object oriented. Dari Pengertian tersebut penulis menyimpulkan bahwa Unified Modeling Language (UML) merupakan bahasa pemodelan yang berbentuk grafis yang digunakan untuk memvisualisasi, menspesifikasikan suatu sistem perangkat lunak [2].

\subsubsection{Class Diagram}

Class adalah sebuah spesifikasi yang jika diinstansiasi akan menghasilkan sebuah objek dan merupakan inti dari pengembangan dan desain berorientasi objek. Class diagram Merupakan diagram yang digunakan untuk menggambarkan pola kelas-kelas dan hubungan antar kelas dari suatu sistem [5].

\subsubsection{Use Case Diagram}

Use case diagram (use case) merupakan pemodelan untuk kelakuan sistem informasi yang akan dibuat. Use case mendeskripsikan sebuah interaksi antara satu atau lebih actor dengan sistem informasi yang akan dibuat. Secara kasar use case digunakan untuk mengetahui fungsi apa saja yang ada di dalam sebuah sistem informasi dan siapa saja yang berhak menggunakan fungsi-fungsi itu. Syarat penamaan pada use case adalah nama didefinisikan sesimpel mungkin dan dapat dipahami. Ada dua hal utama pada use case yaitu pendefinisian apa yang disebut actor dan use case [5].

\subsubsection{Activity Diagram}

Activity diagram menggambarkan berbagai alir aktivitas dalam sistem yang sedang dirancang, bagaimana masing-masing alir berawal, decision yang mungkin terjadi, dan bagaimana mereka berakhir. Activity diagram yang menggambarkan logika prosedural, proses bisnis, alur kerja atau aktivitas, dan skenario dalam sebuah proses [5].

\subsection{Entity Relationship Diagram (ERD)}

Entity Relationship Diagram (ERD) adalah diagram yang menjelaskan data dan objek. Deskripsi ini disebut entitas yang diambil berdasarkan dari objek dunia nyata serta relasi antar entitas dengan penggunaan beberapa notasi standar. Tahap ini bertujuan mengintegrasikan data dalam basis data [6].

\subsection{Sublime Text 3}

Sublime Text 3 adalah text editor berbasis Python, sebuah text editor yang elegan, kaya fitur, cross platform, mudah dan simple yang cukup terkenal di kalangan developer (pengembang) dan desainer. Sublime Text 3 digunakan sebagai editor dari bahasa pemrograman PHP dalam melakukan pengelolaan konten di dalam aplikasi server [7].

\subsection{MySQL}

My Structured Query Language (MySQL) adalah salah satu database popular dan mendunia. Intinya MySQL bekerja menggunakan SQL Language (Structure Query Language). Itu dapat diartikan bahwa MySQL merupakan standar penggunaan database di dunia untuk pengolahan data [5]. 


\subsection{PHP}

PHP merupakan suatu bahasa pemrograman yang difungsikan untuk membangun suatu website dinamis. PHP berjalan pada sisi server, sehingga PHP di sebut juga sebagai bahasa Server Side Scripring, artinya bahwa dalam setiap/untuk menjalankan PHP, wajib membutuhkan web server dalam menjalankannya [5].

\section{Metode Pengabdian masyarakat}

\subsection{Metode Perancangan Sistem}

Pengembangan perangkat lunak Sistem Informasi Pengaduan Layanan BPKAD Provinsi NTB menggunakan kaidah software engineering. Perangkat lunak ini dikembangkan dengan menggunakan metode perancangan sistem waterfall. Metode waterfall dipilih karena prosesnya mengalir secara sistematis dari satu tahap ke tahap yang lain [8].

Metode waterfall tepat digunakan untuk pengembangan sistem informasi pengaduan layanan ini dikarenakan sistem yang dibangun tidak memiliki fitur yang rumit dan batasan pengembangan yang tidak luas. Tahapan pengembangan metode waterfall ini dimulai dari tahap analisis kebutuhan sistem lalu menuju ke tahap analisis, desain, coding, testing/verification, dan maintenance yang dapat dilihat pada Gambar 1.

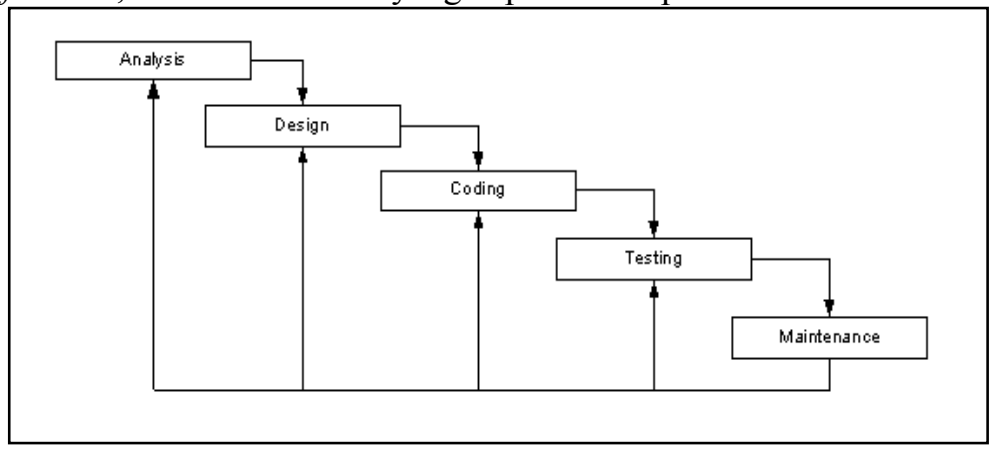

Gambar 1. Tahapan pengembangan waterfall

\subsection{Desain Sistem}

Perancangan desain Sistem Informasi Pengaduan Layanan Badan Pengelolaan Keuangan Dan Aset Daerah Provinsi NTB terdiri dari entity relationship diagram, use case diagram, activity diagram, dan desain interface sistem.

\subsubsection{Use Case Diagram}

Use Case Diagram dalam Sistem Informasi Pengaduan Layanan Badan Pengelolaan Keuangan Dan Aset Daerah Provinsi NTB ini bertujuan untuk menjelaskan apa saja yang dapat dilakukan oleh seorang aktor di dalam sistem. Use Case Diagram dari Sistem Informasi Pengaduan Layanan Badan Pengelolaan Keuangan Dan Aset Daerah Provinsi NTB dijelaskan pada Gambar 2.

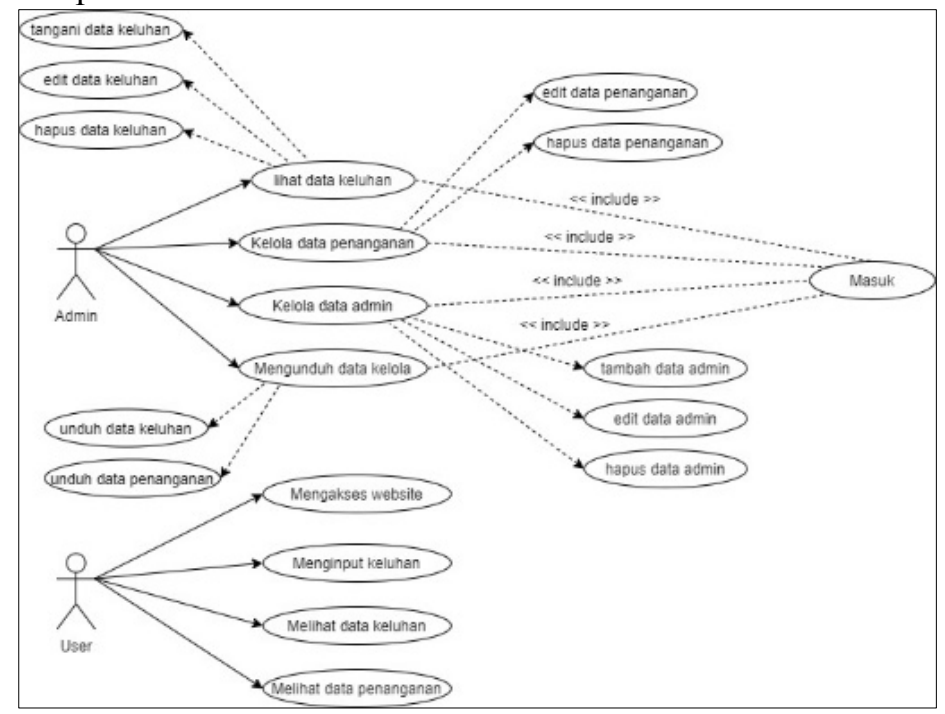

Gambar 2. Use case diagram 
Use case diagram pada Gambar 2 merupakan diagram use case Pada Sistem Informasi Pengaduan Layanan BPKAD Provinsi NTB berbasis web. Diagram di atas menunjukkan bahwa ada 2 aktor yang dapat menggunakan sistem ini, yaitu admin dan user. Berikut perincian proses yang dapat dilakukan oleh aktor :

1. Admin

Proses-proses yang dapat dilakukan Admin dalam sistem sebagai berikut:
a. Login
b. Melihat data keluhan
c. Menangani data keluhan
d. Mengedit data keluhan
e. Menghapus data keluhan
f. Mengunduh data keluhan
g. Melihat data penanganan
h. Mengedit data penanganan
i. Menghapus data penanganan
j. Mengunduh data penanganan
k. Melihat data admin
1. Menambah data admin
$\mathrm{m}$. Mengedit data admin
n. Menghapus data admin
o. Logout

2. Pengguna
a. Mengakses website
b. Memberikan keluhan
c. Melihat data keluhan
d. Melihat data penanganan

\subsubsection{Entity Relationship Diagram (ERD)}

Entity relationship diagram dari Sistem Informasi Pengaduan Layanan Badan Pengelolaan Keuangan dan Aset Daerah Provinsi NTB dapat dilihat pada Gambar 3.

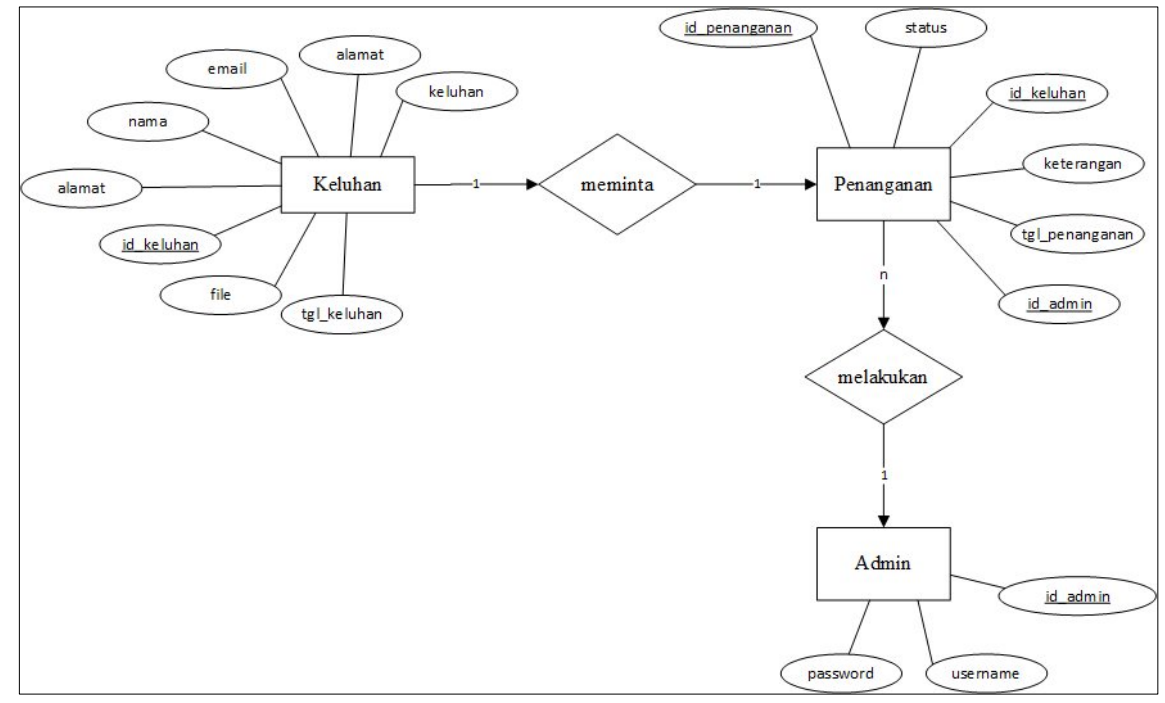

\subsubsection{Class Diagram}

Gambar 3. ERD Sistem Pengaduan Layanan.

Class diagram dari Sistem Informasi Pengaduan Layanan Badan Pengelolaan Keuangan dan Aset Daerah Provinsi NTB yang menggambarkan relasi antar kelas pada sistem dapat dilihat pada Gambar 4. 


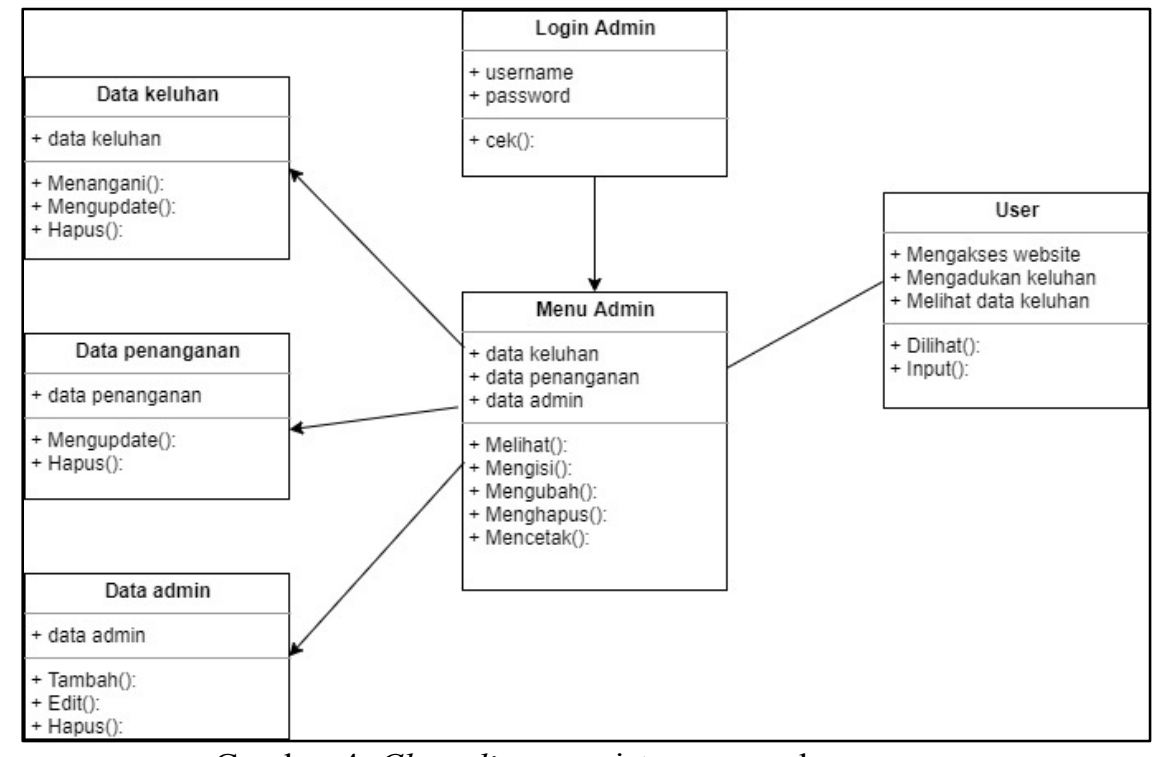

Gambar 4. Class diagram sistem pengaduan

\subsubsection{Activity Diagram}

Activity Diagram pada Sistem Informasi Pengaduan Layanan Badan Pengelolaan Keuangan dan Aset Daerah Provinsi NTB digunakan untuk menggambarkan setiap proses yang terdapat pada sistem. Berikut activity diagram dari keseluruhan proses yang terdapat pada sistem pengaduan layanan.

a. Proses login admin

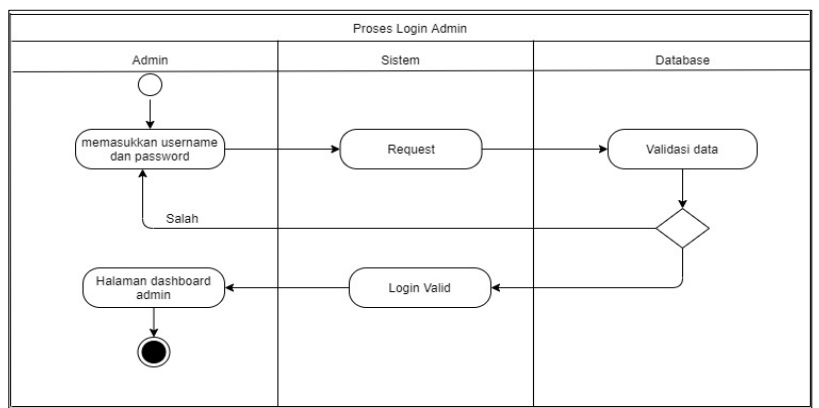

Gambar 5. Activity diagram proses login admin

Pada diagram aktivitas di atas menggambarkan proses pada saat admin akan melakukan proses login ke sistem, di mana admin diharuskan mengisi username dan password terlebih dahulu.

b. Proses tangani data keluhan user

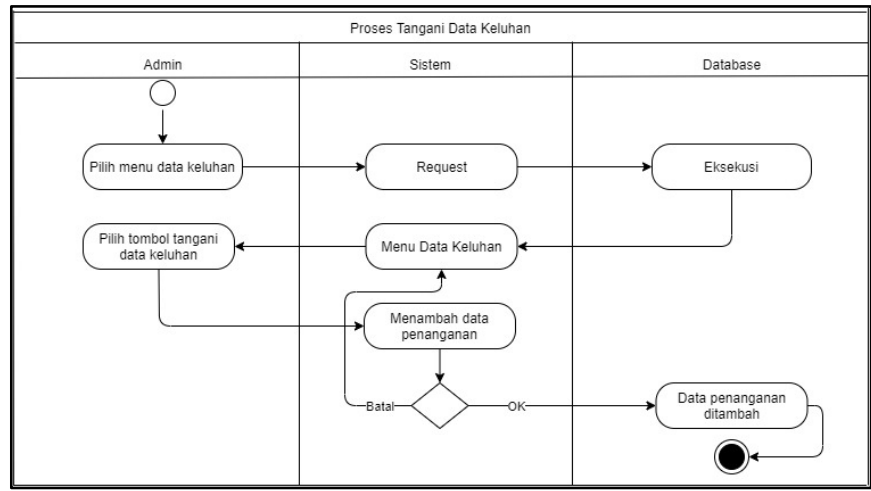

Gambar 6. Activity diagram proses tangani keluhan 
Pada diagram aktivitas di atas menggambarkan proses pada saat admin menangani keluhan user, yakni mengakses menu keluhan terlebih dahulu.

c. Proses hapus data keluhan user

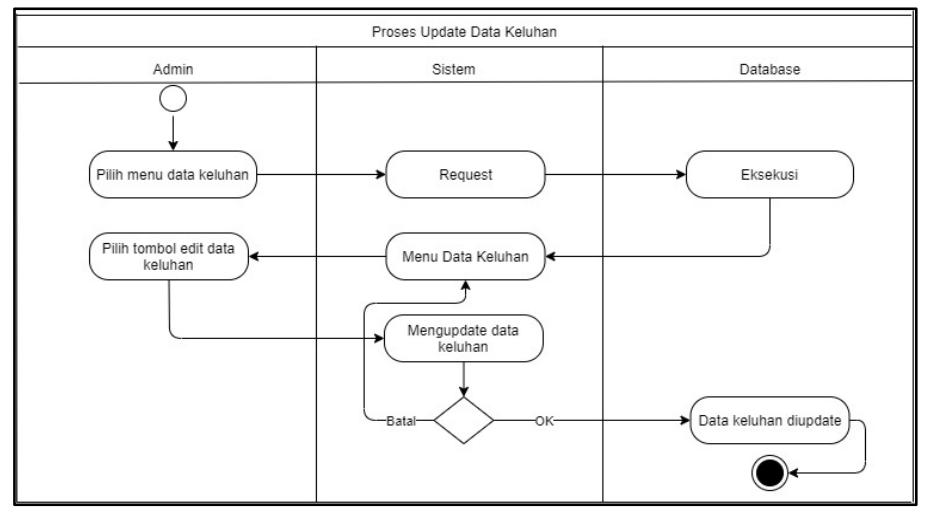

Gambar 7. Activity diagram proses hapus data keluhan

Pada diagram aktivitas di atas menggambarkan proses pada saat admin akan melakukan proses penghapusan data keluhan yang telah dimasukkan oleh user.

d. Proses update data penanganan user

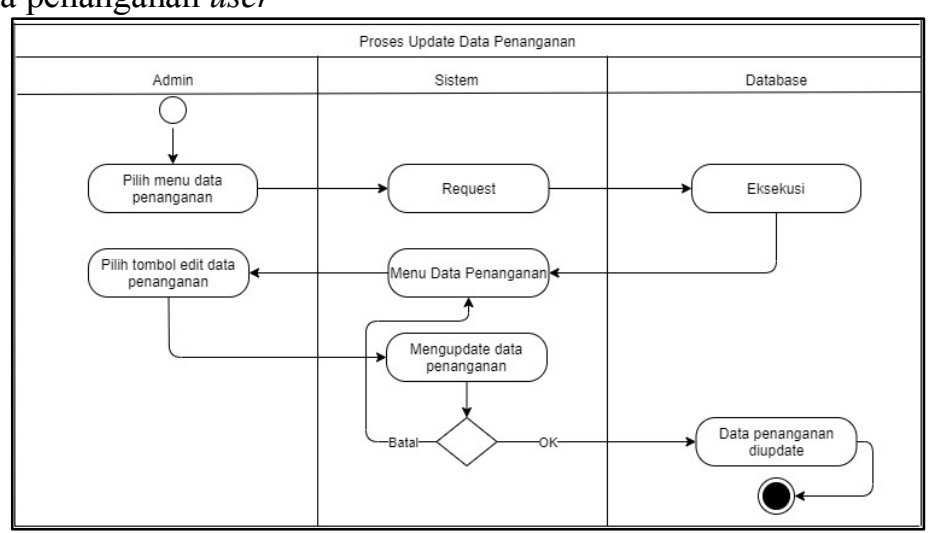

Gambar 8. Activity diagram proses update data penanganan

Pada diagram aktivitas di atas menggambarkan proses pada saat admin akan melakukan update data penanganan.

e. Proses tambah data admin

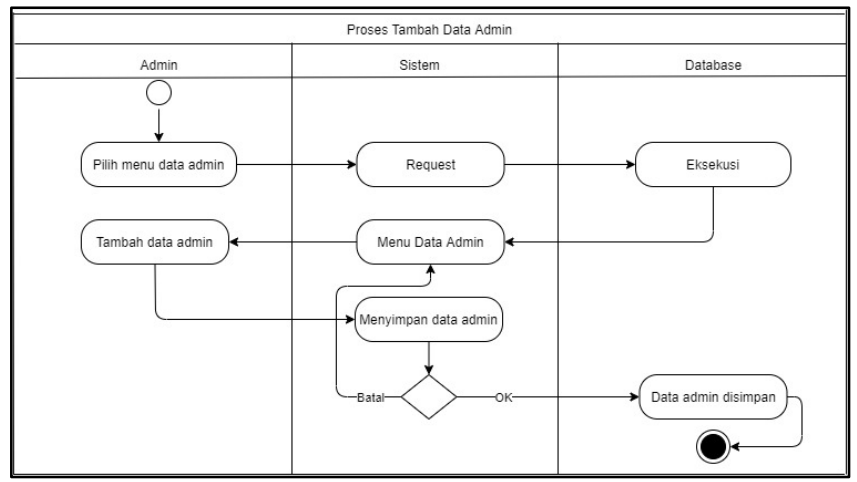

Gambar 9. Activity diagram proses tambah admin

Pada diagram aktivitas di atas menggambarkan proses pada saat admin akan melakukan proses tambah admin baru ke dalam sistem. 
f. Proses input keluhan user

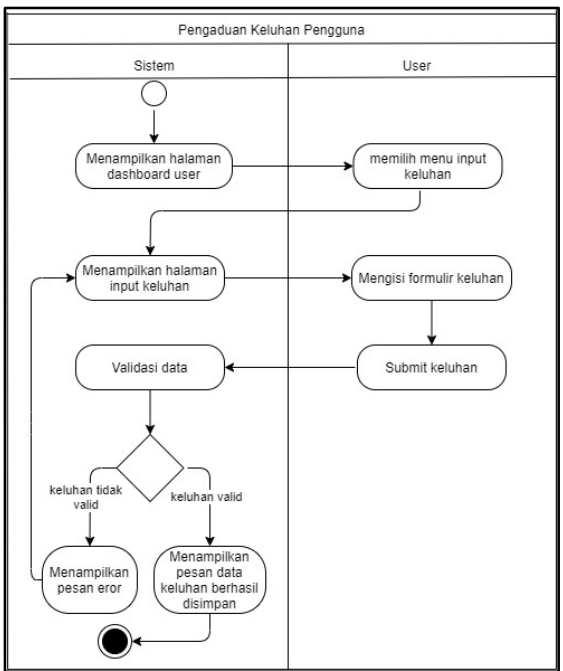

Gambar 10. Activity diagram proses input keluhan

Pada diagram aktivitas di atas menggambarkan proses pada saat user akan memasukkan keluhan ke dalam sistem.

\section{HASIl DAN PEMbahasan}

\subsection{Implementasi Sistem}

Berikut ini adalah implementasi interface dari Sistem Informasi Pengaduan Layanan Badan Pengelolaan Keuangan Dan Aset Daerah Provinsi Nusa Tenggara Barat.

a. Halaman Login Admin

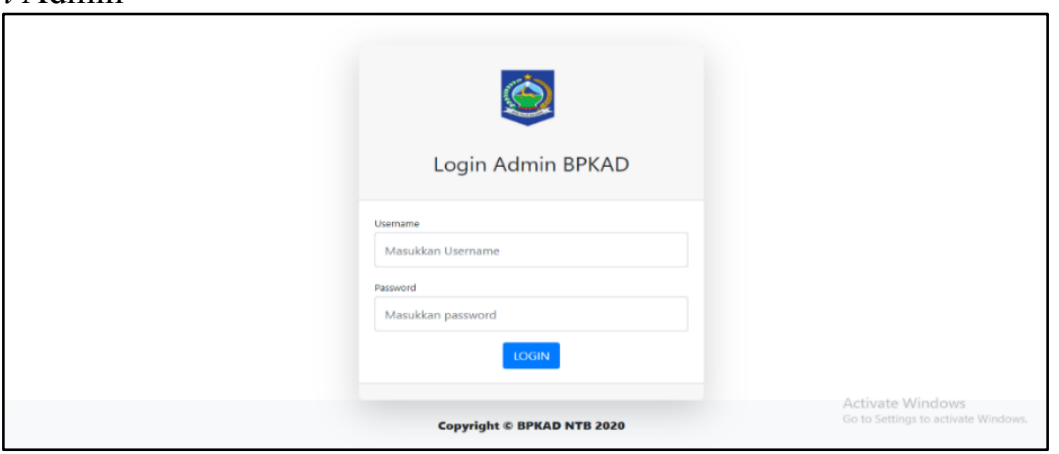

Gambar 11. Halaman login admin

Pada Gambar 11 di atas merupakan tampilan dari halaman login admin untuk melakukan proses login sebelum dapat masuk ke dalam sistem.

b. Halaman Dashboard Admin

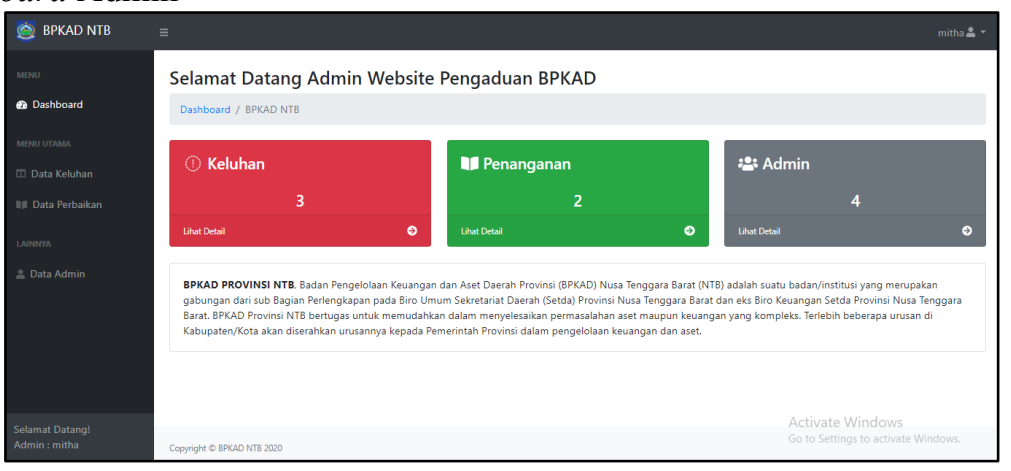

Gambar 12. Halaman dashboard admin 
Pada Gambar 12 di atas merupakan tampilan dari halaman dashboard admin yakni halaman utama yang akan muncul setelah admin berhasil melakukan proses login.

c. Halaman Data Keluhan

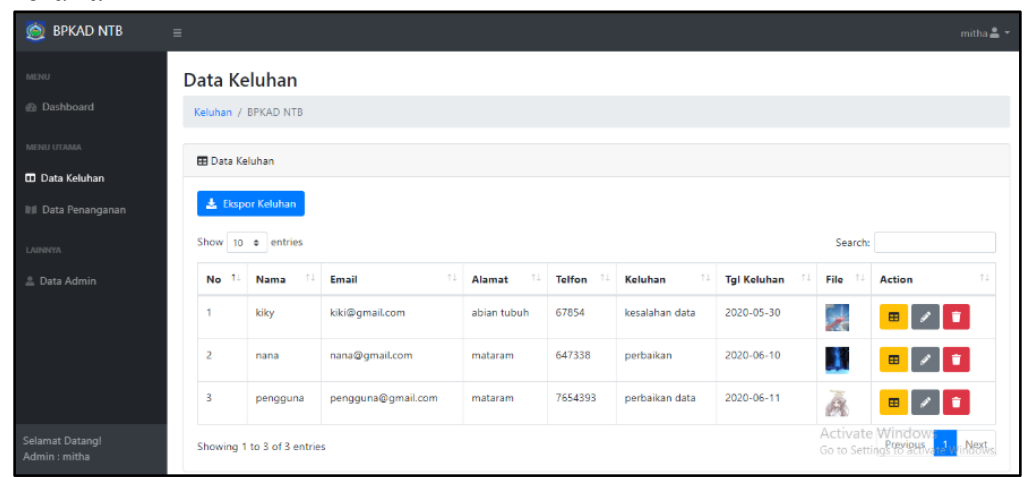

Gambar 13. Halaman data keluhan

Pada Gambar 13 di atas merupakan tampilan dari halaman data keluhan, pada halaman ini admin dapat mengelola setiap keluhan yang telah dilaporkan oleh user dan mengunduh data dalam bentuk file pdf.

d. Halaman Data Penanganan

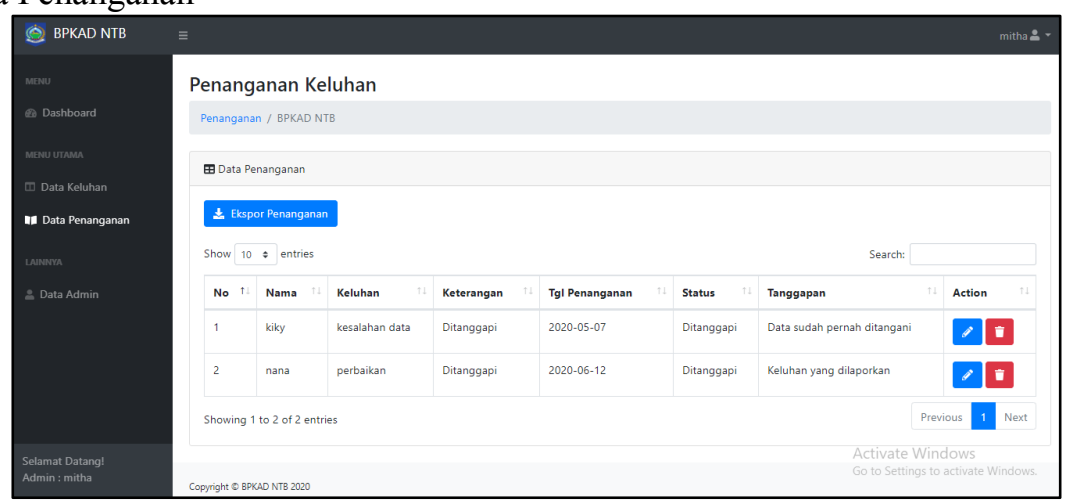

Gambar 14. Halaman data penanganan

Pada Gambar 14 di atas merupakan tampilan dari halaman data penanganan yang berisi data-data dari keluhan yang telah ditangani oleh admin, pada halaman ini admin dapat mengelola data penanganan serta mengunduh data penanganan yang terdapat pada sistem.

e. Halaman Tangani Data Keluhan

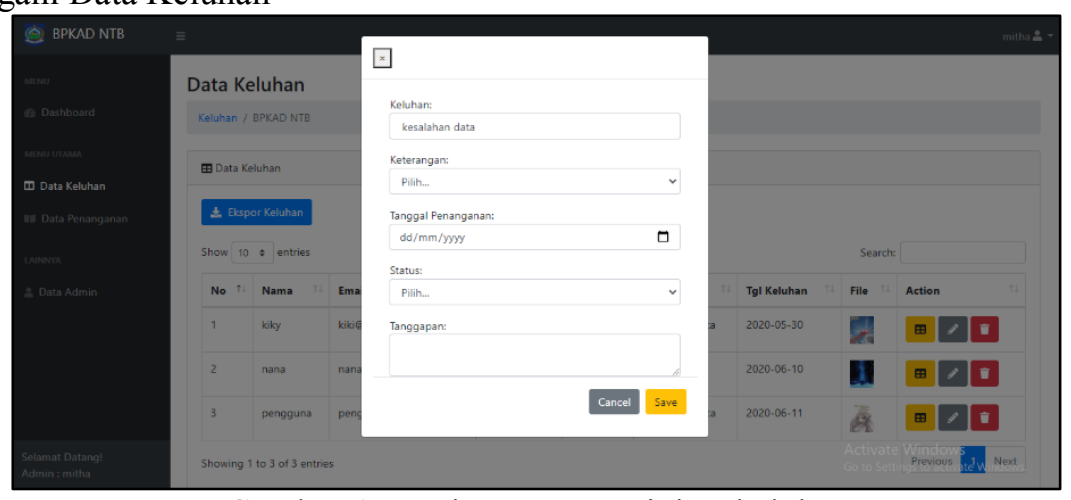

Gambar 15. Halaman tangani data keluhan

Pada Gambar 15 di atas merupakan tampilan dari halaman data keluhan, di mana terdapat form untuk menangani data keluhan. Pada form yang muncul tersebut admin dapat memindahkan data dari keluhan yang dipilih ke data penanganan dengan mengisi keterangan, tanggal penanganan, serta status dari keluhan yang dipilih untuk kemudian data tersebut ditangani. 
f. Halaman Data Admin

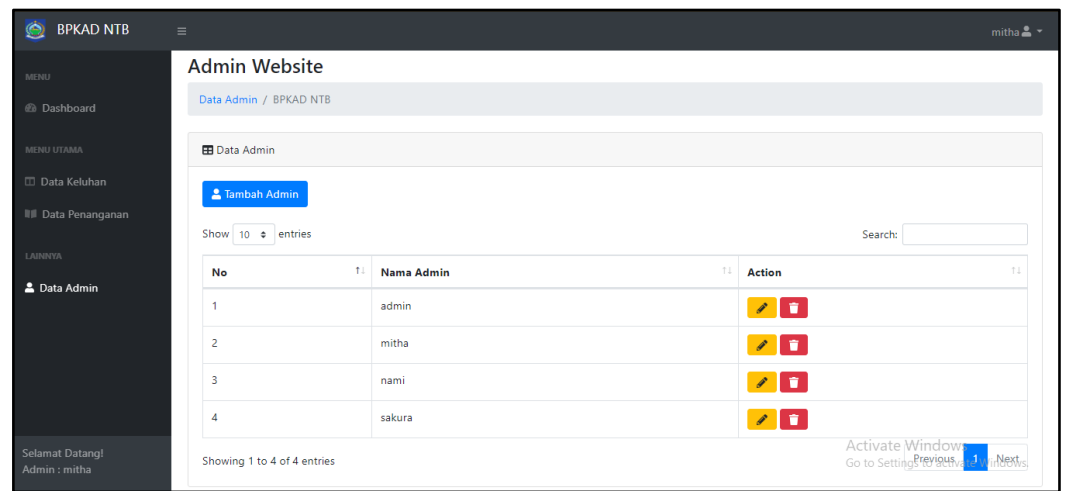

Gambar 16. Halaman data admin

Pada Gambar 16 di atas merupakan tampilan dari halaman data admin yang berisi data-data admin dari sistem, pada halaman ini admin dapat menambah admin baru serta mengelola data admin.

g. Halaman Input Keluhan User

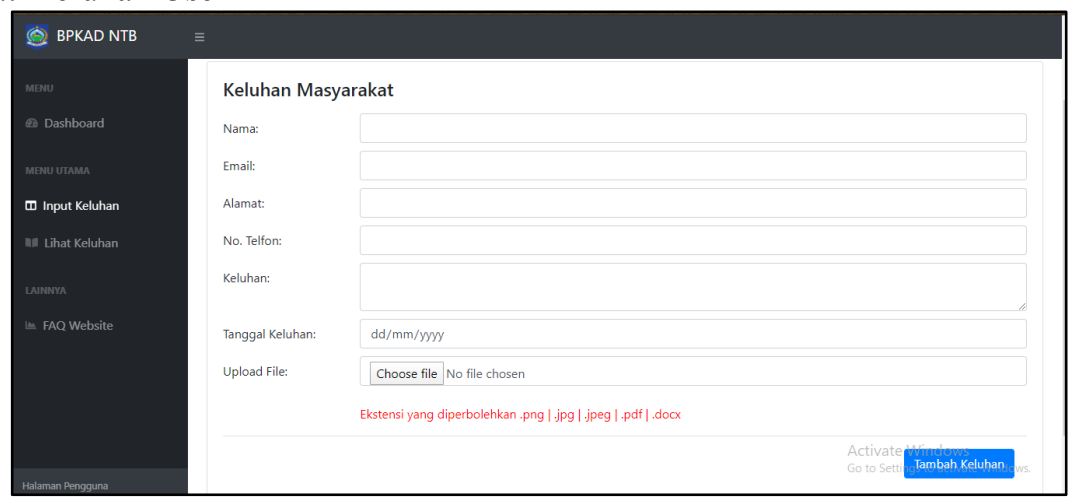

Gambar 17. Halaman input keluhan

Pada Gambar 17 di atas merupakan tampilan dari halaman input keluhan user, pada halaman ini user dapat melaporkan keluhan yang didapat dengan cara mengisi data yang diminta pada sistem.

h. Halaman Lihat Data Penanganan User

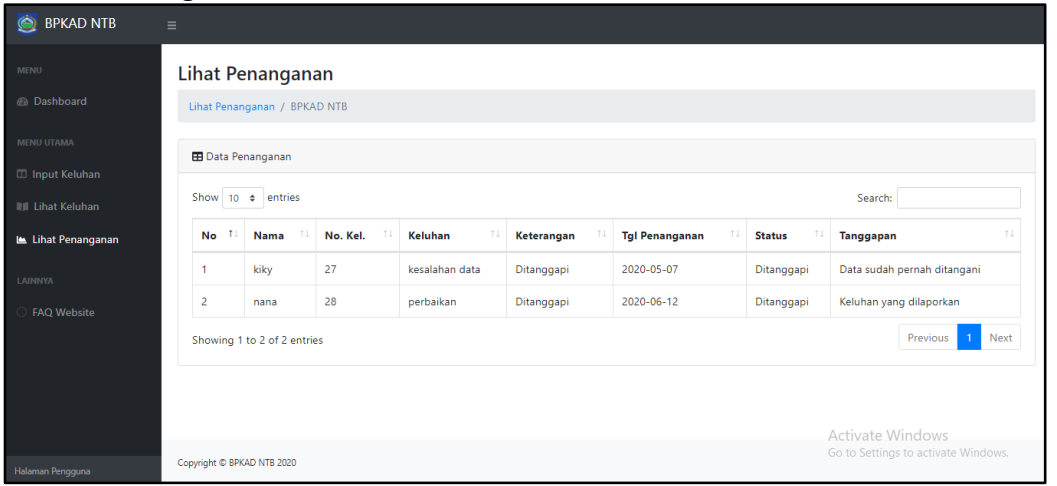

Gambar 18. Halaman lihat data penanganan user

Pada Gambar 18 di atas merupakan tampilan dari halaman lihat data penanganan user, pada halaman ini user dapat melihat data-data yang telah ditangani oleh admin sistem. 
i. Halaman FAQ Website

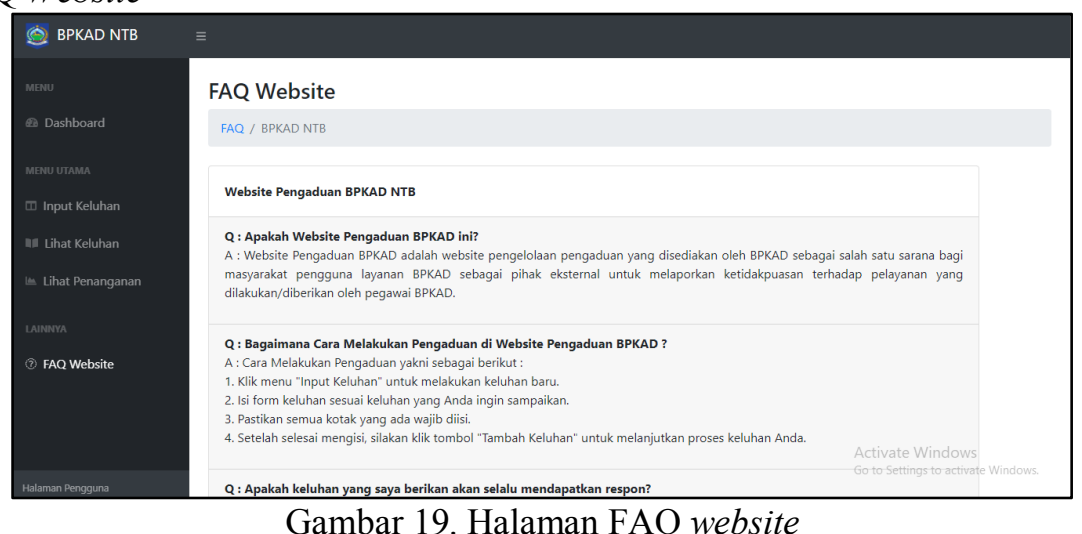

Pada Gambar 19 di atas merupakan tampilan dari halaman FAQ website, pada halaman ini berisi pertanyaan dan jawaban seputar website yang dapat membantu user dalam menggunakan sistem.

\subsection{Pengujian Kuesioner Pegawai}

Setelah proses implementasi sistem dilakukan, kemudian dilakukan tahapan selanjutnya yakni pengujian sistem pada pihak Badan Pengelolaan Keuangan dan Aset Daerah (BPKAD) Provinsi Nusa Tenggara Barat. Pengujian sistem ini dilakukan dengan cara melakukan uji coba sistem secara langsung dengan responden yakni pegawai BPKAD Provinsi NTB. Dari hasil uji coba sistem tersebut kemudian dilakukan proses uji kelayakan sistem dengan mengisi kuesioner dari pegawai BPKAD Provinsi NTB.

Berdasarkan pertanyaan-pertanyaan yang terdapat pada kuesioner sebagai uji kelayakan sistem, diberikan pilihan jawaban yakni sebagai berikut :
a. $\mathrm{SS}=$ Sangat Setuju
b. $\mathrm{S}=$ Setuju
c. $\mathrm{C}=$ Cukup
d. $\mathrm{TS}=$ Tidak Setuju
e. STS $=$ Sangat Tidak Setuju

TABEL 1. HASIL PENGUJIAN KUESIONER

\begin{tabular}{|c|l|c|c|c|c|c|}
\hline \multirow{2}{*}{ No. } & \multicolumn{1}{|c|}{ Pernyataan } & \multicolumn{3}{c|}{ Pilihan Jawaban } \\
\cline { 3 - 6 } & \multicolumn{1}{|c|}{ SS } & S & C & TS & STS \\
\hline 1. & Tampilan sistem sudah baik dan mudah digunakan & 3 & 1 & 1 & 0 & 0 \\
\hline 2. & $\begin{array}{l}\text { Sistem memenuhi kepuasan pengguna selama } \\
\text { penggunaan }\end{array}$ & 0 & 5 & 0 & 0 & 0 \\
\hline 3. & Fitur dalam sistem dapat mempermudah pekerjaan & 4 & 1 & 0 & 0 & 0 \\
\hline 4. & Pengelolaan data pada sistem sudah baik & 1 & 4 & 0 & 0 & 0 \\
\hline 5. & $\begin{array}{l}\text { Sistem sudah memenuhi syarat sesuai kinerja } \\
\text { instansi }\end{array}$ & 3 & 2 & 0 & 0 & 0 \\
\hline Tata - Rata (\%) & 11 & 13 & 1 & 0 & 0 \\
\hline
\end{tabular}

Berdasarkan hasil pengujian kuesioner pada Tabel 1 yang telah dilakukan, maka didapatkan total keseluruhan dari pernyataan responden yakni berjumlah 25 poin dan terdiri dari SS (Sangat Setuju) berjumlah 11 poin dengan persentase sebesar $44 \%$, S (Setuju) berjumlah 13 poin dengan persentase sebesar $52 \%$, dan C (Cukup) berjumlah 1 poin dengan persentase sebesar $4 \%$. Dapat disimpulkan bahwa sistem ini sangat berguna untuk membantu para pegawai BPKAD Provinsi Nusa Tenggara Barat dalam mengelola data keluhan masyarakat. 


\section{KESIMPULAN DAN SARAN}

\subsection{Kesimpulan}

Berdasarkan hasil pengabdian masyarakat yang dilakukan di Kantor Badan Pengelolaan Keuangan dan Aset Daerah (BPKAD) Provinsi Nusa Tenggara Barat berupa pembangunan Sistem Informasi Pengaduan Layanan BPKAD NTB berbasis web, dapat diambil beberapa kesimpulan sebagai berikut:

a. Sistem informasi Pengaduan Layanan ini telah memenuhi syarat sesuai kinerja instansi sesuai dengan kuesioner hasil pengujian yang diisi oleh pihak BPKAD dengan persentase jawaban sebesar $88 \%$, serta fiturfitur pada sistem juga dapat memudahkan pengelolaan keluhan bagi admin sistem dengan persentase jawaban sebesar $96 \%$.

b. Pada pengujian, proses-proses pada sistem sudah memenuhi kepuasan pengguna yang terbukti dari hasil uji kelayakan sistem dengan persentase jawaban sebesar $80 \%$.

c. Rancang Bangun Sistem Informasi Pengaduan Layanan BPKD Provinsi Nusa Tenggara Barat ini sudah sangat baik dan mudah digunakan oleh pegawai BPKAD dan user sesuai dengan hasil kuesioner dengan persentase jawaban $88 \%$. Serta pengelolaan data pada sistem juga sudah baik terbukti dengan persentase jawaban dari uji kelayakan sistem sebesar $84 \%$.

\subsection{Saran}

Adapun saran yang dapat diberikan penulis agar Sistem Informasi Pengaduan Layanan Badan Pengelolaan Keuangan dan Aset Daerah Provinsi NTB ini menjadi lebih baik di masa yang akan datang, agar dalam pengembangan ke depannya sistem informasi pengaduan layanan ini dapat dikembangkan lagi dalam hal tampilan dan terutama fitur dan fungsinya agar bisa ditambahkan.

\section{DAFTAR PUSTAKA}

[1] T. Sutabri, Konsep Sistem Informasi, vol. 3, no. 1. 2012.

[2] Y. Heriyanto, "Perancangan Sistem Informasi Rental Mobil Berbasis Web Pada PT.APM Rent Car," J. IntraTech, vol. 2, no. 2, pp. 64-77, 2018.

[3] M. A. S. Suripto and R. A. Triyono, "Pembangunan Sistem Informasi Akta Kelahiran," Indones. J. Netw. Secur., vol. 3, no. 3, pp. 33-40, 2014, [Online]. Available: http://ijns.org/journal/index.php/ijns/article/view/403.

[4] J. T. Elektro and P. N. Medan, "Perancangan Website Pada Pt . Ratu Enim Palembang," pp. 15-27, 2012.

[5] H. Irsyad, "Penerapan Metode Waterfall Pada Aplikasi Perumahan Di Kota Palembang Berbasis Web Mobile (Studi Kasus Pt. Sandaran Sukses Abadi)," J. Tek. Inform. Musirawas, vol. 3, no. 1, p. 9, 2018, doi: 10.32767/jutim.v3i1.310.

[6] M. Mustianti, I. B. Ketut Widiartha, and M. A. Albar, "Sistem Informasi Tugas Akhir Program Studi Informatika," J. Teknol. Informasi, Komputer, dan Apl. (JTIKA ), vol. 2, no. 1, pp. 19-29, 2020, doi: 10.29303/jtika.v2i1.43.

[7] Suparwanto and Diah Pradiatiningtyas, "E-Learning Sebagai Media Pembelajaran Berbasis Web Pada Smk N 4 Purworejo," Suparwanto, Diah Pradiatiningtyas, vol. 7, no. 2, pp. 1-8, 2017, [Online]. Available: https://ijns.org/journal/index.php/ijns/article/download/1499/1460.

[8] I. B. K. Widiartha, N. M. Puspitayanti, and S. E. Anjarwani, "Rancang Bangun Sistem Informasi Akreditasi Sekolah," J. Teknol. Informasi, Komputer, dan Apl. (JTIKA ), vol. 1, no. 1, pp. 41-48, 2019, doi: 10.29303/jtika.vli1.18. 